\title{
Salmonella Hepatitis in Children : An Update
}

\author{
S Kadir ', T Begum², M R Islam ${ }^{3}$, G Nabi ${ }^{4}$, M A Haque ${ }^{5}$ \\ N S Hoque ${ }^{6}$, B H N Yasmeen ${ }^{7}$
}

1 Dr. Sadika Kadir

MBBS, MD (Paediatric Gastroenterology) Assistant Professor, Paediatrics Z.H. Shikder Womens Medical College, Dhaka

2 Prof. Dr. Tamanna Begum MBBS, MD, DCH, MPH,

Prof. and Head

Dept. of Paediatric

3 Dr. Md . Rafiqul Islam

MBBS, DCH

Associate Professor

Dept. of Paediatrics

4 Dr. Golam Nabi

MBBS (DMC), MRCP (London)

Associate Professor of Medicine

5 Dr. Md. Ashraful Haque MBBS,MS (Neurosurgery)

Assistant Professor, Neurosurgery National Institute of Neuroscience Dhaka

${ }^{6}$ Dr. Naima Sharmin Hoque MBBS, FCPS, FIAOG

Fellow Gynae Endoscopic Surgery

Dept. of obstetrics and gynaecology

$2,3,4,6$

Z. H. Shikder Womens Medical College, Dhaka

7 Prof. Dr.B H Nazma Yasmeen

Professor and Head

Dept. of Paediatrics

Northern International Medical

College, Dhaka

Correspondence

Dr.Sadika Kadir

Assistant Professor, Paediatrics

Z.H.Shikder Womens Medical College

E-mail_dr.sadika_maruf@yahoo.com

\section{Abstract}

Salmonella hepatitis is one of the atypical presentations of typhoid fever and can be defined as reversible involvement of liver during the course of typhoid fever. There have been more than 150 cases of salmonella hepatitis reported both in developed and developing countries. The documented incidence varies widely from 1 to $26 \%$ of patients with Typhoid fever. It presents with jaundice and tender hepatosplenomegaly. Investigation shows slightly raised transaminase levels with or without 5 adenosine neucleosidase and or decreased prothombin time index. It complicates into hepatic encephalopathy and bleeding diathesis. A positive culture for Salmonella from blood or stool is essential to differentiate Salmonella hepatitis from other causes of acute hepatitis. Hepatic pathology is characterized by the presence of typhoid nodules with marked hyperplasia of reticuloendothelial system.

The ALT/LDH ratio $<9$ is suggestive of Salmonella hepatitis which is $>9$ in viral hepatitis. The prognosis is usually good as Salmonella hepatitis responses with specific antibiotic therapy and jaundice resolves with clinical improvement. The clinical course can be severe with high mortality $(20 \%)$ sometime. In our country where enteric fever is endemic, the recognition of Salmonella hepatitis is of clinical importance .

Key Words : Typhoid fever, Hepatomegaly, Salmonella hepatitis, Transaminase, Viral hepatitis.

\section{DOI: https://doi.org/10.3329/nimcj.v10i2.45436}

Northern International Medical College Journal Vol. 10 No. 2 January 2019, Page 397-399

\section{Introduction}

Typhoid fever is a very common infectious disease of tropics, associated with high morbidity and mortality in children. ${ }^{1,2}$ It can involve virtually all the system of the body and can present with various presentations. Hepatic involvement was first reported by William Osler in $1899 . .^{1-3}$ Salmonella hepatitis is a recently coined term to describe the hepatic complications of typhoid fever. It is a separate entity and has its own clinical presentation and diagnostic tools. Recognition of Salmonella hepatitis is of clinical importance as it can mimic acute viral hepatitis., ${ }^{3,4}$ Early diagnosis and institution of specific therapy can improve the prognosis in these patients.

\section{Definition}

According to Pakistan Society of hepatology guideline 2017, a patient is labeled as suffering from Salmonella hepatitis (also called typhoid hepatitis) if he / she fulfills the following 3 or 4 criteria. ${ }^{5-7}$

(a) Hepatomegaly, (b) Jaundice, (c) Biochemical abnormalities - serum bilirubin > $30.6 \mathrm{umol} / \mathrm{l}$, SGOT/SGPT raised with or without 5'adenosine nucleotides and/or prolonged prothrombin time, (d) Abnormal liver histopathology

\section{Epidemiology}

Involvement of liver in typhoid is more commonly seen in endemic areas but has also been reported from non-endemic areas. Acute hepatitis prevalence due to Salmonella is $1 \%$ to $26 \%$ of patients. ${ }^{6}$

No age is exempted from typhoid hepatitis, but it is commonly seen between second and fourth decades and in patients belonging to lower socioeconomic class. ${ }^{7}$ Complications like hepatitis occur more in patients with depressed cellular immunity and in those with relapse of typhoid fever. As shown in Table1more than 150 cases of salmonella hepatitis reported in the literature. The majority of the reports were in patients with typhoid infection but it can also occur in patients with paratyphoid infection. The organisms most often responsible for the complication of hepatitis in the paratyphoid group are S. Paratyphi types A and B. ${ }^{8}$ The reported incidence of salmonella hepatitis ranges from $0.426 \%$ of cases of typhoid fever and is highest from a study in Vietnam. The most frequent reports are from India where $4-8 \%$ of 
patients with typhoid fever had salmonella hepatitis. Some of the reported patients are associated with other complications of typhoid fever (e.g. encephalopathy, bleeding diathesis or renal failure). Nevertheless, salmonella hepatitis is not mentioned in several large reviews of severe complications of salmonella infection (e.g. typhoid intestinal perforation jaundice due to bacterial infection or salmonella bacteremia with septic metastasis). There are no known definite predisposing factors for salmonella hepatitis, although the occurrence appears to be more common in adult male patients, but can also occur in 410-year-old childrens and in the elderly.

As salmonella hepatitis appears to be more common in the East, it is not yet clear whether there is a relationship between a genetic susceptibility to the bacterial toxin in an individual. The hepatic involvement has been proposed to be more common and more likely to be severe in patients with anaemia, malnutrition, poor health and in those with relapsed infections or when a latent infection is activated. Salmonellosis is an important infection in immune-compromised hosts, in particular human immunodeficiency virus (HIV) positive patients. In comparison with the normal population, salmonella infection is 15-100 times more common in patients with HIV positive/acquired immunodeficiency syndrome (AIDS). ${ }^{9}$

Table 1: Reports of liver involvement in typhoid fever (in percentage) shafquat et al 19949

\begin{tabular}{|l|c|c|c|c|c|}
\hline \multicolumn{1}{|c|}{ Study } & $\begin{array}{c}\text { No of } \\
\text { patients }\end{array}$ & Jaundice & Hepatomegaly & $\begin{array}{c}\text { Abnormal } \\
\text { LFT }\end{array}$ & $\begin{array}{c}\text { Abnormal liver } \\
\text { histology }\end{array}$ \\
\hline Stuart and Pullen & 360 & 3.6 & 25 & NR & NR \\
Rowland 961 & 530 & 1.1 & NR & NR & NR \\
Gulati et al.1968 & 98 & 0 & 0 & NR & NR \\
Wicks et al. 1971 & 243 & 1.6 & 7.6 & NR & NR \\
Ramachandran et al. 1976 & 58 & 7.6 & 29 & - & - \\
Diem et el. 1974 & 15 & 26.6 & 10 & 93.3 & NR \\
Samantray et el. 1977 & 500 & 0 & 18 & NR & NR \\
Singh et el. 1978 & 460 & 1 & NR & NR & NR \\
Nasrallah and Nassar 1978 & 104 & 23 & 33 & 17 & NR \\
Johnson and Aderele. 1981 & 117 & 26 & 27 & 5 & NR \\
Gupta et el. 1985 & 125 & 5.6 & 8.8 & 5.6 & NR \\
Khosla et el. 1988 & 36 & 8.3 & 55 & 55 & 40 \\
Ishaq et al. 1990 & 30 & 0 & 63 & NR & NR \\
Arif et el. 1990 & 9 & 66 & 77 & NR & NR \\
Shafquat et el. 1994 & 31 & 45 & 70 & 100 & 44 \\
Karoli et el. 2012 & 1 & 1 & 1 & NR & 1 \\
\hline
\end{tabular}

\section{Pathogenesis}

Pathogenesis of Salmonella Hepatitis is not clear. More commonly seen in malnourished people belonging to lower socio-economic group. ${ }^{10}$

Bacteremia may be the cause of liver damage as bacteremia occurs in most patients with typhoid fever. Salmonella endotoxin has been implicated in causing Salmonella hepatitis like other features of typhoid fever. When these bacilli enter the circulation after considerable multiplication in lymphoid tissue of intestine, they undergo destruction with the liberation of endotoxin which produces the symptoms of typhoid fever. The possibility of localized intravascular coagulation and arteritis in the pathogenesis of clinical features of typhoid fever. Hepatic injury could be due to vascular hyperactivity due to catecholamine's,
Immune complexes and high ratio of antitrypsin to C3 have been seen in typhoid fever and more frequently in patients with complications like hepatitis. ${ }^{11}$

\section{Clinical features}

Clinical features would be both of typhoid fever and that of hepatic involvement. Onset of fever in typhoid is slow and insidious in most of the cases but rapid onset with or without chills has also been observed. ${ }^{12}$ The most common prodromal symptoms which precede the actual onset of fever is headache, malaise and anorexia. ${ }^{13,14}$ Abdominal pain, constipation, diarrhea abdominal distension, body aches and pains and symptoms pertaining to chest e.g. cough, sore throat may be present. Common physical signs are fever, toxemia, typhoid tongue, splenomegaly, hepatomegaly, relative-bradycardia, rose spots and abdominal tenderness. ${ }^{15}$ Features indicative of hepatic involvement which may be present alone or in combination are hepatomegaly, jaundice, altered liver function tests and abnormal histology. ${ }^{16}$

\section{Investigations}

Mild to moderate anemia, hypoproteinemia, hypoalbuminemia, mild thrombocytopenia, deranged transaminases and alkaline phosphatase levels are usually observed in patients with typhoid hepatitis. ${ }^{17}$ More serious cases of may present with deranged clotting profile (raised prothrombin time, bleeding time and clotting time). ${ }^{17}$ Though transaminase levels are high in patients with salmonella hepatitis, but they are not as high as in viral hepatitis patients. The admission ALT/LDH ratio is the best discriminator between both entities. The serum ALT: LDH ratio levels (expressed in multiples of upper limit of normal) was found to be less than 9 in typhoid hepatitis and more than 9 in acute viral hepatitis. Hepatocyte dysfunction or secondary bone marrow involvement can present with bleeding diathesis in more serious patients. ${ }^{18} \mathrm{~A}$ liver biopsy in patients with salmonella hepatitis is expected to reveal cloudy swelling, ballooning, degeneration with vacuolation, moderate fatty change and mononeuclear cell infiltration in few focal areas with minimal portal tract infiltration without any focal necrosis. ${ }^{19}$ Table 2 shows the list of investigations for establishing Salmonella hepatitis.

\section{Table 2 : Investigation of Salmonella hepatitis}

\section{Investigations}

- Complete blood count and Peripheral blood film

$0 \quad$ Widal test

- Blood, stool and urine culture

- Bone marrow aspirate

o Liver function Test- Serum bilirubin, ALT, AST, PT, AlkalinePhosphatase, 5 adenosine neucleotidase

$0 \quad$ ALT/LDH ratio

- Liver biopsy 


\section{Complications}

Salmonella hepatitis is usually mild and runs a benign course and may even be missed by the physician or it can be severe presenting with severe bleeding syndrome, hematemesis or hepatic encephalopathy. Patient with Salmonella encephalopathy do not usually have asterixis/hepatic flap as opposed to patients in hepatic encephalopathy from other causes. ${ }^{19}$

\section{Diagnosis}

Diagnosis of Salmonella hepatitis is based on confirmation of typhoid fever and that of liver involvement. Typhoid fever can be confirmed by isolation of the organisms from culture of different media e.g. Blood, bone marrow aspirate, rose spots, urine, faeces and bile. Most important of these are blood and bone marrow cultures. Bone marrow culture is considered to be the most sensitive single method for isolating these organisms especially in patients who have already used antibiotics. Diagnosis can be confirmed by changes in biopsy specimens from liver or kidney. Serological tests e.g. Widal test may help in diagnosis though with certain reservations. Formation of agglutinins (antibodies) against their antigens within the body, form the basis of this test. ${ }^{19,20}$

\section{Differential Diagnosis ${ }^{19,20}$}

\section{Viral Hepatitis}

\begin{tabular}{|c|c|c|}
\hline & Viral hepatitis & Salmonella hepatitis \\
\hline Clinical features & $\begin{array}{l}\text { M arked anorexia } \\
\text { and fever usually } \\
\text { precede the illness } \\
\text { and as jaundice } \\
\text { appears, the fever } \\
\text { subsides }\end{array}$ & $\begin{array}{l}\text { Fever and jaundice co-exist at the peak } \\
\text { of the disease course. }\end{array}$ \\
\hline Histopathologically & $\begin{array}{l}\text { In viral hepatitis } \\
\text { there is acute } \\
\text { diffuse } \\
\text { inflammation with } \\
\text { necrosis of the liver } \\
\text { cells but without } \\
\text { any fatty change. }\end{array}$ & $\begin{array}{l}\text { Salmonella hepatitis shows cloudy } \\
\text { swelling, ballooning, degeneration with } \\
\text { vacuolation, moderate fatty change and } \\
\text { mononeuclear cell infiltration in few } \\
\text { focal areas with minimal portal tract } \\
\text { infiltration without any focal necrosis }\end{array}$ \\
\hline ALT/LDH ratio & $\begin{array}{l}\text { If greater than 9, it } \\
\text { is suggestive } \\
\text { of viral hepatitis. }\end{array}$ & $\begin{array}{l}\text { If less than 9, it is suggestive of } \\
\text { salmonella hepatitis; }\end{array}$ \\
\hline
\end{tabular}

\section{Malarial Hepatitis}

In malarial hepatitis, there is Kupffer cell hyperplasia with brown pigmentation and non-specific granulomatous lesions.

\section{Amoebic Hepatitis:}

Focal necrotic areas are seen in amoebic hepatitis.

\section{Treatment}

Treatment of typhoid hepatitis is like enteric fever. Complications like hepatic encephalopathy and bleeding diatheses require specific treatment. ${ }^{20}$

\section{First line}

Treatment of Salmonella hepatitis is the same as that of typhoid fever
๑ Chloramphenicol a Cotrimoxazole

$\checkmark$ Amoxycillin, Ciprofloxacin, Ofloxacin

\section{Second Line}

- Cephalosporins-Cefoperazone, Cefixime $\square$ For treatment of Carriers-Ampicillin, Amoxicillin, Trimethoprim sulphamethoxazole.

\section{Prognosis}

The prognosis is usually good as Salmonella Hepatitis responds well to a specific antibiotic therapy and resolves with clinical improvement. ${ }^{21}$ The clinical course can be severe with a mortality rate as high as $20 \%$, particularly with delayed treatment or in complications of salmonella infections. ${ }^{22}$

\section{Conclusion}

In our country where Typhoid fever is endemic in children with high fever, jaundice rise in transaminase and bilirubin Salmonella hepatitis is a probable diagnosis. We must consider that Salmonella hepatitis responds to proper antibiotic therapy and has an excellent prognosis.

\section{References}

1. Osler W. Hepatic complications of typhoid fever. Johns Hopkins Hosp Rep 1899, 8: 373-387.

2. Ayhan A, Gokoz A. \& Karacadag, S. The liver in typhoid fever. Am J Gastroenterol 1973, 59: 141146.

3. Rao PN, Bhusnurmath SR, Naik SR. Typhoid fever manifesting with haematemesis, hepatitis and haemolysis. J Trop Med Hyg 1978, 81: 146-149.

4. Karr P, Bhargava DK, Tandon B.N. Enteric hepatitis. J Assoc Physicians India 1985, 33: 417-418.

5. Khosla SN. Changing patterns of typhoid-A reappraisal. Asian Med J 1982, 25 185-198.

6. Shafquat F, Anwar A, Iqbal Z.Salmonella Hepatitis:A Reveiew.S.Z.P.G.M.I vol: 8(3-4) 1994,78-88.

7. Mohammad W, Badshah A, Haider I.Management of Salmonella Hepatitis.PSH Clinical Guideline Statement 2017.

8. Pramoolsinsap C, Virunvatti V.Salmonella Hepatitis:Review.Journal of Gastroenterology \& Hepatology(1998) 13,745-750.

9. Levine WC, Buehler JW, Bean NH, Tauxe RV. Epidemiology of non-typhoida salmonella bacteremia during the human immunodeficiency virus epidemic. J. Infect. Dis $1991,64: 81-7$

10. Singh DS. Typhoid hepatitis. J Assoc Physicians India 1985, 33: 621.

11. Sherlock S. Diseases of the Liver and Biliary System, sixth edition. Blackwell Scientific Publications, Oxford, London, 1981, p. 431-446.

12. Butler $T$, Williams R, Ball J. Typhoid fever-studies of blood coagulation, bacteremia and endotoxemia. Arch Intern Med 1978, 137: 407-410.

13. Koff SR, Schiff L, Schiff ER . Diseases of the Liver. J.P. Lippincott, Philadelphia, Toronto 1982, p. 461-610.

14. Greig HB, Naidoo PD. A case of typhoid fever complicated by severe bleeding syndrome due to deficiency of prothrombin group of coagulating factors. J Trop Med Hyg 1981, 84: 253-257.

15. Faierman D, Rose FA, Seckler SG. Typhoid fever complicated by hepatitis, nephritis and thrombocytopenia. JAMA 1972, 221: 60-62.

16. Khosla SN, Srivastava SC, Gupta SP. Neuropsychiatric manifestations of typhoid. J Trop Med Hyg 1977, 80:95-98.

17. Stuart BM, Pullen RI. Typhoid-clinical analysis of 360 cases. Arch Ind Med 1946, 78: 629-667.

18. Balasubramanian S, Kaarthigeyan K, Srinivas S, Rajeswari R. Serum ALT: LDH ratio in typhoid fever and acute viral hepatitis. Indian Pediatr 2010;47:339-41.

19. Khosla SN, Singh R, Singh GP. The spectrum of hepatic injury in enteric fever. Am J Gastroenterol 1988, 83: 413-416.

20. Ramachandran S, Godfrey JJ. Perera M.V.F. Typhoid hepatitis. JAMA 1974 230: 236-240

21. Nasrullah SM, Nassar VH. Enteric fever . Am J Gastroenterol 1978, 69:63-69.

22. Karoli R, Fatima J, Chandra A, Singh G.Salmonella Hepatitis: An Uncommon Complication of a common Disease. J Fam Med Primary Care 2012:1;160-2. 